Article

\title{
The Relationship between Training Satisfaction and the Readiness to Transfer Learning: The Mediating Role of Normative Commitment
}

\author{
Jamal Ben Mansour ${ }^{1, *}$, Abdelhadi Naji ${ }^{1}$ and André Leclerc ${ }^{2}$ \\ 1 Human Resources Department, University of Quebec in Trois-Rivières, 3351 des Forges BLVD, P.O. Box 500, \\ Trois-Rivières, QC G9A 5H7, Canada; abdelhadi.naji@uqtr.ca \\ 2 Administration Department, University of Moncton, 18 Antonine-Maillet Avenue, Moncton, NB E1A 3E9, \\ Canada; andre.leclerc@umoncton.ca \\ * Correspondence: jamal.ben.mansour@uqtr.ca; Tel.: +1-819-376-5011 (ext. 3146)
}

Academic Editor: Yongrok Choi

Received: 4 March 2017; Accepted: 10 May 2017; Published: 16 May 2017

\begin{abstract}
Organizations are becoming increasingly demanding in regard to training cost rationalization and justification, and to the associated result achievement obligation. In practice, these pressures result in the introduction of more or less adequate efficiency indicators in relation to training programs. The goal of this study is to understand the relationship between training and training efficiency indicators at the individual level, using a mediation model. This study proposes a three-factor mediation model estimated using a databank of 578 cases. The results first show a positive relation between training satisfaction and normative commitment. Normative commitment has a positive effect on readiness to transfer learning and a negative effect on absenteeism. Theoretical and practical implications are discussed in light of these findings.
\end{abstract}

Keywords: training satisfaction; readiness to transfer learning; normative commitment

\section{Introduction}

Workplace training relates to the employee's acquisition and systematic development of the skills-behavior (knowledge, skills, and social behavior) required to adequately perform tasks and improve work performance [1,2]. According to the Conference Board of Canada, Canadian organizations spent an average of $\$ 800$ per employee on formal training and skills development programs in 2014 and 2015, a 17\% increase from 2010. The same source indicates that about $50 \%$ of organizations have singled out providing employee learning as a number one priority. Practitioners believe that the inordinate spending on learning is based on the belief that workplace training is a major lever for organizational performance, competitiveness, and innovation $[3,4]$, and that an investment of this kind will pay off in improved financial results $[5,6]$. In addition, if training supports their skills, career development and employability, employees can gain as much as the organization from training [7]. That is what refers to intellectual capital, which contributes to creating a company's long-lasting value [8]. In a nutshell, workplace training is a strategic pillar of human resource management (HRM), which benefits employees, work teams, organizations, and society at large $[9,10]$.

However, while individual employee rewards of learning are empirically supported [11-13], organizational benefits in terms of productivity, quality, customer service, and financial returns are minor (the effect size is 0.21 according to the meta-analysis by Tharenou, Saks \& Moore [14]). In addition, they are both hard to define universally [15] and attribute to trained employees only, and they are contingent upon contextual factors other than the training (for example, the alignment 
between training and strategic planning). In addition, reaction and learning outcomes (the first and second levels of Kirkpatrick's training evaluation model) on the one hand, and behavior and results (the third and fourth levels of the same model) on the other, are weakly correlated $[16,17]$. In their attempt to explain the modest intercorrelations found in Reference [16] between the different levels of criteria in Kirkpatrick's training evaluation model, Alliger and colleagues [17] explored a moderator analysis based on the closeness of criteria to training content (that is, on the content validity of the measures). In a related vein, and beyond the content validity of the measure, we think that reaction to training may create a trainee psychological state that predisposes and leads him/her to transfer the learning. Therefore, we decided to introduce a proximal outcome to trainee reaction, named "readiness to transfer". Consequently, the belief in the virtues of training is not held by all practitioners, and each training or skills development program creates discrepancies in the manager's thoughts regarding training as an investment in employee development and as a risky expenditure. The following are some examples of such fears based on the risky side of training: training might boost artificially the skills requirements for current job positions, leading to an increased payroll and future recruitment costs; competitors will poach trained employees; the rapid obsolescence of new skills, especially in fields such as information technology, require continued investment in training; the cost-effectiveness relating to the direct and indirect costs of training is difficult to demonstrate; there may be employee turnover before the organization obtains a return on its investment in training, which constitutes a partial human capital loss and generates additional costs related to recruitment; the job market is shifting towards non-standard employment (part-time jobs, for example) not necessarily involving training; the availability of trained employees on the job market encourages organizations to acquire rather than develop employee skills; insecure jobs lead employees to prefer training that enhances their employability rather than their work performance; and there is a tendency to provide excessively narrow training so as to prevent competitors from benefiting from an employee's training once he or she has left the organization.

In order to resolve this tension between the need to introduce training and skills development programs and doubts in regards to the impact and benefits thereof for the organization itself, the Training-Results relationship evaluation grid needs to be revisited. The emerging literature $[18,19]$ proposes an initial look at the impact on proximal outcomes (the micro level, i.e., the direct impact of training on the individual employee), which can subsequently play a mediating role in the Training-Results relationship, using distal outcomes such as organizational performance and financial results (the macro level, i.e., the direct impact of training on the organization). It should be noted that macro level outcomes may depend directly on the training or on other contingent factors. Therefore, we recognize that the combination of micro and macro levels provides a better understanding of the complex relationship between training and outcomes at different levels, but that using only macro level indicators to evaluate training can skew the Training-Results relationship evaluation, thus stoking negative beliefs about training.

This study aims to examine a new manner of evaluating the Training-Results relationship, involving on one hand the introduction of proximal factors relating to the trained employee, namely the affective reaction to the training, the sense of moral obligation to transfer learning, and the willingness to do so, and on the other hand, exploring the underlying mechanisms linking these different factors. The focus on training proximal factors, i.e., on the employee level, is important because it provides answers to questions that are more relevant to the understanding of the Training-Results relationship. For example, it is much more interesting to get a grasp on the role that the employee's perception of the training plays than to count the number of employees trained or the number of training programs introduced. It is indeed difficult to assume that merely increasing investment and programs for learning will suffice to produce results [20-22], without taking into account the reaction of the employee to these programs. In the same vein, the organization cannot expect a return on its investment in training until the transfer of learning has been tangibly felt in employees' daily work. Transfer of learning is ascertained by the conjunction of three elements that relate directly to the trained employees, namely 
their decision not to leave the organization, not to be absent from the workplace, and to use their newly acquired knowledge for the benefit of the organization. It is possible that other factors influence the Training-Results relationship, but we believe that a good investment in training must first and foremost lead to the following three proximal effects: to get the employee to remain within the organization (retention effect); to be present (workplace attendance effect); and to harness his or her knowledge for the benefit of the organization (personal commitment effect). The goal of this study is to verify the effect and the mechanism underlying the relationship between a positive reaction to the training offered and trained employees' attitudes (readiness to transfer learning) and behavior (reduced absenteeism).

\section{Literature Review and Hypotheses}

\subsection{Human Capital Theory}

According to human capital theory, human capital is a subset of the global notion of capital. It is an asset, a stock of knowledge and experience accumulated by its holder throughout his/her life. According to Schultz [23], both knowledge and skills are a "form of capital". He defined human capital as a set of knowledge, skills, and abilities that are inherent and used by the individual. Becker [24] affirms that tangible assets are not the only forms of capital. For him, education, medical care, and moral values are also examples of capital.

To achieve sustainable positive results, organizations need to be proactive in the way they exploit their resources, particularly those that are considered intellectual capital [25]. Although different taxonomies have been proposed to identify intellectual capital, they share the fact that human capital is part of the intellectual capital of the organization [26]. When employees acquire new knowledge, the human capital value, the intellectual capital, and the market value of the business are enriched. Due to the importance of human capital, it is essential that a company improves the level of knowledge, skills and attitudes of its employees [25]. Therefore, an organization can make investment decisions for employee development. All of this depends on people, and getting the best from people depends on understanding what motivates them to perform better [27].

Human capital theory supports the importance of investing in training and employee development. Obviously, employees take advantage of these opportunities to increase their employability and their market value. This situation reinforces the cost-benefit tensions that weigh on managers. This research focuses on the reaction of employees in order to reduce the consequences of these tensions.

\subsection{Social Exchange and Reciprocity}

Since initial works of the social exchange theorists in the 1920s, different views have emerged in different disciplines, especially social psychology (e.g., [28-30]) and sociology (e.g., [31]). Despite the multiplication of thoughts around the concept of social exchange, they all share the idea of the accumulation over time of interactions between two or more social actors which generate a certain obligation between these actors [32]. Stability within social systems and cumulative interaction are possible only in the presence of norms or rules favoring the durability of the social exchange relationship such as "reciprocity norm" or repayment. It was Gouldner [28] who explicitly introduced reciprocity norm as a pillar of social exchange:

I suggest that a norm of reciprocity, in its universal form, makes two interrelated, minimal demands: (1) people should help those who have helped them, and (2) people should not injure those who have helped them. Generically, the norm of reciprocity may be conceived of as a dimension to be found in all value systems and, in particular, as one among a number of "Principal Components" universally present in moral codes (p. 171).

According to Gouldner [28], reciprocity norm is a widely accepted social rule. It refers to an expectation that people respond to each other in similar ways and may be motivated by at least three 
mechanisms. First, reciprocity may be motivated by the desire to receive future favors and maximize personal interest; it can be labeled "utilitarian reciprocity". Second, "normative reciprocity" refers to the need to reduce indebtedness, a kind of feeling of obligation to reciprocate. Third, "attraction reciprocity" is emotion-focused and may be motivated by the desire to increase attractiveness between recipient and donor.

This aspect of the norm and rule was demonstrated in several organizational studies [33]. Indeed, the employee-employer relationship includes both an economic and social exchange. For example, employer investment in training could be encouraged by expected employee work behavior in terms of skills mobilization developed during training. In fact, the reciprocity norm explains that the support received by an employee from one source (for example, the organization) creates an obligation to return this support in some way.

\subsection{Workplace Training and Satisfaction with Training}

Satisfaction with workplace training involves two very different but interrelated concepts: training as a HRM activity and the learner's satisfaction thereof. First of all, training is one of the main mandates of any human resource department. It refers to a set of activities aimed at reducing underperformance and/or increasing employee potential through skills-behavior development (knowledge, skills, and social behavior). In regards to job satisfaction, it is defined as the way employees feel about their employment situation, i.e., to what degree they like or do not like their job and its various aspects ([34], p. 2). When job satisfaction is limited to the training received, we speak of satisfaction with training, which refers to the extent of an employee's appreciation or lack thereof in regards to employer-planned activities for the purpose of developing the knowledge and skills required for the job [35].

Satisfaction with workplace training informs on the affective and attitudinal post-training response of the learner (trained employee). It is a multi-faceted evaluation that makes it possible to grasp the appreciation experienced by the learner on the level of emotion and in terms of usefulness. It refers to the third component of learning (cognitive, skill-based, and affective, and to the first of the four training evaluation criteria in Kirkpatrick's model [36], which are reaction, learning, behavior or transfer, and results. In this paper, we adopt Schmidt's definition of satisfaction in training as “... how people feel about aspects of the job training they receive. Job training satisfaction is the extent to which people like or dislike the set of planned activities organized to develop the knowledge, skills, and attitudes required to effectively perform a given task or job" ([35], p. 483). However, according to Schmidt [35], the definition of training satisfaction has three major implications: (i) the focus is on job training as a whole, rather than on a single training course; (ii) the evaluation targets formal or planned training activities offered by the organization rather than informal learning efforts initiated by employees or their colleagues; and (iii) it refers to the general reaction to elements before and after the training, such as satisfaction with the training and the motivation to transfer learning (post reaction), and the motivation to undergo training (a priori reaction).

\subsection{Relationship between Satisfaction with Training and the Readiness to Transfer Learning}

In the context of formal training and skills development programs provided by the organization, the importance of satisfaction with training lies in its impact, positive or negative, on post-training attitudes and behavior. Studies are not consistent in this regard. Schmidt's study [35] shows a positive relationship between satisfaction with training and overall job satisfaction $(r=0.73)$. Other studies demonstrate a weak and non-significant relationship between satisfaction with training and transfer of learning ( $r=0.03$ in the study by Colquit et al. [15]; $r=0.07$ in the research by Alliger et al. [17]). In other terms, a positive reaction to the training does not necessarily imply transfer of learning. These results contradict the hypotheses underlying Kirkpatrick's model [36], which establishes a positive relationship between a positive reaction to the training and transfer of learning. The issue of transfer has been studied extensively following the publication of Baldwin and Ford's model [37]. More recently, Rivard and Lauzier [38] built on this and other models to divide barriers to transfer into 
three categories: (i) barriers relating to the learner; (ii) barriers relating to the immediate supervisor; and (iii) barriers relating to the work environment. Our focus for the purpose of this study is on the first category, and it refers to two separate but interrelated obstacles: satisfaction with training and readiness to transfer learning [39].

According to Tannenbaum, Mathieu, Salas and Cannon-Bowers [40], reactions to training reflect the meeting of expectations and actual experience. Before taking the training course, learners develop expectations in regard to their integration within the organization or improved performance or employability, and their actual experience determines their post-training attitudes and behavior, including satisfaction with the training, motivation to transfer learning, and actual transfer of learning. It is plausible that the discrepancy between Kirkpatrick's theoretical proposal [36], that of Colquit et al. [15], and the empirical testing of Alliger et al. [17] is due to another mechanism that connects a positive reaction to the training to a more proximal outcome than the transfer, referring directly to the learner, namely his or her readiness to transfer learning. More specifically, when pre-training expectations meet the actual experience thereof, reflected in satisfaction with training, it is possible to infer that the employee's reaction after the training is positive and will indeed be reflected in his or her readiness to transfer learning. In other words, an emotional reaction to the training then leads to a psychological state that is favorable to transfer. In the following paragraphs, we lay out our belief that normative commitment to the organization plays a role in this transformation.

\subsection{Normative Commitment to the Organization}

For over 40 years, a large volume of research was dedicated to the notion of commitment to the organization, and to the background and consequences thereof. Today, the connection between commitment and behavior such as turnover, absenteeism, work performance, and organizational citizenship is widely accepted. Coming on the heels of Mowday et al. [41] and O'Reilly and Chatman's [42] work, Meyer and Allen [43] initially broadened the two-dimensional model (affective and calculative) by defining commitment as a "psychological state that (a) characterizes the employee's relationship with the organization, and (b) has implication for the decision to continue or discontinue membership in the organization" ([44], p. 67). Meyer and Allen also draw on the theory of reasoned action and other previous research [45-47] in order to show the importance of subjective norms in the prediction of individuals' behavior, which reflects the usefulness of a third form of commitment, i.e., normative commitment. The three component model (TCM) thus emerged [48], including (i) affective commitment-emotional attachment, identification with the organization and its values and mission ("I stay because I want to"); (ii) normative commitment-feeling a sense of obligation to stay with the organization ("I stay because I ought to"); (iii) continuance commitment-commitment out of a feeling of necessity on the basis of perceived losses if the individual left the organization and the absence of better alternatives ("I stay because I need to").

Of the three types of commitment [44], normative commitment was the latest to emerge in the literature and remains by far the least studied. This type of commitment was first introduced in the literature in the 1980s by Wiener and colleagues [45,46], through what has become known as the normative approach to commitment. This type of commitment is initially defined as internalized normative pressures to act in a way that meets organizational interests, based on identification and loyalty. According to this perspective, employees are willing to make personal sacrifices for the good of the organization because they believe that this is the moral way to behave. The normative approach to commitment is an extension of the traditional commitment model based on identification only (affective commitment) but it contrasts with instrumental motivation (calculative commitment), where behavior is determined on the basis of costs and benefits. According to Wiener, this type of commitment is dependent on individual beliefs, culture, family, and organizational involvement, such as recruitment, selection, socialization, and so on.

Along the same line of thought, Scholl ([47], p. 593) defines commitment as "a stabilizing force that acts to maintain behavioral direction when expectancy/equity conditions are not met and do 
not function." However, Wiener and Scholl's propositions differ in terms of explanatory mechanism. In Wiener's view, individuals act by moral duty, whereas according to Scholl, they conform to a moral duty, which is to give back. Scholl opines that individuals tend to continue to act in this manner until the balance is struck between what they have received (training, for example), and what they have given back (harnessing knowledge, for example). From the standpoint of his approach, individuals' behaviors are explained mainly by interiorized norms, in this case reciprocity [28].

\subsection{Relationship between Satisfaction with Training, Readiness to Transfer Learning, and Normative Commitment}

Since Wiener theorized normative commitment, it has been the object of a number of conceptual reconfigurations, and it is now widely recognized that this type of commitment refers to a feeling of obligation towards the organization (to remain with the organization or to support imposed changes) [49]. This duty proceeds from the interiorized norm of reciprocity [28]: a moral precept that is necessary for sustaining any kind of social exchange [31]. The main implication of these conceptual and theoretical developments is the importance of the motivation that underlies normative commitment, often overlooked or underutilized, in particular when commitment is the result of a sense of moral obligation toward the organization [50]. The most recent work on normative commitment addresses the aspect of motivation within the meaning of self-determination theory (SDT) [51,52]. According to this theory, motivation varies along a continuum reflecting the degree of autonomy of the individual in regulating his or her behavior: externally regulated behavior, introjected regulation of behavior, regulation through identification, and integrated regulation. Meyer et al. [53] draw links between the three-component model of commitment and self-determination theory insofar as calculative commitment relates to external regulation, affective commitment is associated with integrated regulation, and normative commitment is characterized by introjected regulation of behavior. The latter is a form of interiorized motivation associated with an internal pressure to act in a manner that satisfies expectations (based on an interiorized norm, attitude, or behavior), in order to avoid shame and guilt, and to maintain self-worth. Meyer and Parfyonova ([50], p. 287) describe in further detail the normative commitment-introjected regulation parallel in order to emphasize that what is at work in this aspect of normative commitment is "a desire to do the right thing" rather than "doing things in order to avoid negative outcomes". On the basis of the reciprocity norm and self-determination theory, we are therefore able to assert that satisfaction with training creates a sense of moral debt to give back to the organization and that normative commitment reflects a moral obligation to do the right thing (give back what the learner owes), meaning to transfer the learning received in the context of training. In addition, as suggested by Bartlett [54], by “adapt(ing) new research methods to demonstrate to organizational decision makers that training and development contributes to desired workplace attitudes ... which may in turn influence behaviors such as absenteeism and turnover" (p. 349), we also anticipate a negative effect of the normative commitment on absenteeism. We therefore put forward the following hypotheses:

Hypothesis 1. Satisfaction with training positively impacts the readiness to transfer learning.

Hypothesis 2. Normative commitment to the organization mediates the relationship between satisfaction with training and the readiness to transfer learning.

Hypothesis 3. Normative commitment to the organization negatively impacts absenteeism.

\section{Research Methodology}

A questionnaire was administered to the employees of a large Canadian financial institution's head office and 15 branch offices, along with a letter explaining the purpose and potential impact of the study, soliciting their participation, and referring them to the survey website. To ensure participants' 
anonymity, the questionnaire was made available online and it contained no identification of the participating employee. Out of a total of 1200 employees, we received 578 valid responses, i.e., a $48 \%$ valid response rate. Survey questions addressed training, normative commitment, willingness to commit, and absenteeism.

\subsection{Measurement}

All variable measurement tools were drawn from the existing literature. For all measurement scales, except absenteeism, respondents were invited to indicate the extent to which they agreed or disagreed with each statement on the Likert five-level scale $(1=$ strongly disagree; $5=$ strongly agree $)$.

\subsubsection{Satisfaction with Training}

According to the definition adopted in this study, satisfaction with training was measured in terms of satisfaction with the overall training offered by the organization and not regarding a specific training or material. Thus, the assessment of satisfaction with training covered different employees' expectations and needs at different levels of their professional cycle, namely training to support integration during organizational entry, training applicability to the job and to improve performance, and training to support career advancement. More specifically, the "satisfaction with training" variable was introduced in this study model as an independent variable and was measured through five statements adapted to the Schmidt scale [35]. This scale makes it possible to grasp perceptions in regard to access to training provided by the employer during a given professional cycle ("My employer provides training upon one's joining the organization", for example) and in regards to training usefulness ("The training offered allows me to improve my work performance", or "The training offered increases my career opportunities", for example). The reliability coefficient, alpha, for this scale is $78 \%$ and its composite reliability is $74 \%$.

\subsubsection{Normative Commitment to the Organization}

Normative commitment was introduced in our model as a mediating variable. It was measured through four adapted statements from Meyer, Allen and Smith's scale [55]. This scale evaluates the sense of moral obligation to remain with the organization ("I am part of the organization because this is what my sense of loyalty commands"). The reliability coefficient, alpha, for this scale is $76 \%$ and its composite reliability is $71 \%$.

\subsubsection{Readiness to Transfer Learning}

The readiness to transfer learning variable was introduced in this model as a dependent variable. It was measured through a single general statement relating to the willingness to expend efforts toward skill development ("I am ready to put in significant effort in my work to help my organization offer high client quality service").

\subsubsection{Absenteeism}

The absenteeism variable was introduced as a dependent variable with five categories $(1=$ not a single day; 2 = between 1 and 3 days; 3 = between 4 and 6 days; 4 = between 7 and 9 days; $5=10$ days or more). According to Statistics Canada [56], the financial sector exhibits an average rate of absenteeism of 8.8 days per year. Category 5 of our variable reflects the critical threshold exceeding the average.

\subsection{Plan of Analysis}

Statistical analyses were carried out using Lisrel 9.2 software. These analyses focused on structural equations based on the bootstrap sampling approach at the time of mediation analysis. The quality of the mediation model lies in the following adjustment indices: chi-squared test (ch2); Comparative Fit Index (CFI); Root Mean Square Error of Approximation (RMSEA); and Standardized Root Mean 
square Residual (SRMR) [57]. Four variables were controlled: (i) gender (male or female); (ii) age group (distribution used by Statistics Canada); (iii) seniority within the organization; and (iv) employee supervision (yes or no).

\section{Results}

\subsection{Sample Characteristics}

Respondent demographic characteristics were the following: approximately half of employees were aged between 26 and 45 (48.7\%). The proportion of younger employees (between 18 and 25) did not exceed $5 \%$, while the proportion of employees aged 46 to 55 represented approximately $37.9 \%$. Respondents were mainly female, i.e., $80.4 \%$ (19.6\% were men). Among employees, $43.9 \%$ had university education and $56.1 \%$ had a high school or college diploma. Finally, $13.3 \%$ held a supervisory position, and $86.7 \%$ of employees did not supervise other employees.

\subsection{Measurement Model}

Table 1 shows the average, standard deviations, reliability coefficients, and correlations with respect to the three constructs being studied (training, normative commitment, and readiness to transfer learning). Prior to testing our hypotheses, we conducted a series of confirmatory factor analyses (CFA) using LISREL (9.2) in order to verify the structure of the constructs used in our research. As indicated in Table 2, we compared by the maximum likelihood function the adjustment of the structural three-factor model (3FM: one factor per construct) to a one-factor nested model (1FM: a one-factor combining the three constructs). We drew two conclusions from the results of these analyses. Firstly, there was a significant difference between the three-factor model (3FM) and the one-factor nested model at the $1 \%$ threshold $(\Delta \operatorname{ch} 2 / \Delta \mathrm{df}=108.3 / 2 ; \varrho<0.001)$. The three-factor model (3FM) exhibited better adjustment indices than the one-factor model (1FM) and was therefore superior $\left(\chi^{2}[18]=37.69 ; \varrho<0.001 ; \mathrm{CFI}=0.97 ; \mathrm{RMSEA}=0.04 ; \mathrm{SRMR}=0.02\right)$. In consequence, the three-factor model (3FM) did not contain redundant constructs and was retained for subsequent analyses.

Table 1. Descriptive statistics, correlations, and reliabilities.

\begin{tabular}{lccccc}
\hline & $\begin{array}{c}\text { Average Scores } \\
\mathbf{1} \text { to } \mathbf{5}\end{array}$ & Standard Deviations & $\mathbf{1}$ & $\mathbf{2}$ & $\mathbf{3}$ \\
\hline 1. Satisfaction with training & 3.92 & 0.73 & $(0.78)$ & \\
2. Normative commitment & 3.76 & 0.87 & 0.60 & $(0.76)$ \\
3. Readiness to transfer & 4.63 & 0.54 & 0.26 & 0.30 & - \\
4. Absenteeism & - & - & - & - & - \\
\hline
\end{tabular}

Note: Independent variable: 1 = training; dependent variables: 2 = normative commitment; 3 = readiness to transfer learning. The alpha coefficients are on the diagonal.

Table 2. Confirmatory factor analyses.

\begin{tabular}{lccccc}
\hline & $\chi^{2}$ & df & CFI & RMSEA & SRMR \\
\hline 1FM: One-Factor Model & 145.99 & 20 & 0.86 & 0.11 & 0.06 \\
3FM: Three-Factor Model & 37.69 & 18 & 0.97 & 0.04 & 0.02 \\
Mod3F vs. Mod1F & $\Delta \mathrm{ch} 2=108.3$ & $\Delta \mathrm{df}=2(\mathrm{sig})$ & - & - & - \\
\hline
\end{tabular}

Note: $\chi^{2}=$ chi square; $\mathrm{df}=$ degrees of freedom; RMSEA $=$ root mean square error of approximation; $\mathrm{CFI}=$ comparative fit index; $\mathrm{SRMR}=$ standardized root mean square residual.

\subsection{Relationship between Training, Normative Commitment, Readiness to Commit, and Absenteeism}

Empirical data support the quality of the factor structures for all variables. Table 2 presents the descriptive statistics and correlations between the variables of interest. More specifically, participants expressed average satisfaction with training and normative commitment 
(Mean $_{(\text {Satisfaction with training) }}=3.92 ;$ Mean $\left._{(\text {Normative commitment) }}=3.76\right)$, but average to strong readiness to transfer learning (Mean (Readiness to transfer learning) $=4.63$ ). Figure 1 shows the relationships of the hypothetical model in structural equations. Results show that satisfaction with training has a positive effect on normative commitment $\left(\beta_{1,1}=0.61, \varrho<0.001\right)$ and a total positive indirect effect on readiness to transfer learning through normative commitment $\left(\beta_{\text {Indirect }}=0.15, \varrho<0.001\right)$. Normative commitment enhances readiness to transfer $\left(\beta_{2,1}=0.24, \varrho<0.001\right)$ and reduces absenteeism (odds ratio $=0.833$; 1 /odds ratio $=1.20, \varrho<0.001$ ). The additional results presented in Table 3 support the viability of a total mediation model. The 95\% confidence interval for "total effects" and for "indirect effects" do not contain 0 value [58], meaning that the relationship between satisfaction with training and readiness to transfer learning becomes non-significant after the introduction of the normative commitment to the organization variable. Consequently, normative commitment is a mediating variable in the context of the relationship between the independent variable, which is satisfaction with training, and readiness to transfer. All the hypotheses of our study model are therefore supported. The model also provides an explanation for the $11 \%$ variance of the readiness to transfer learning.

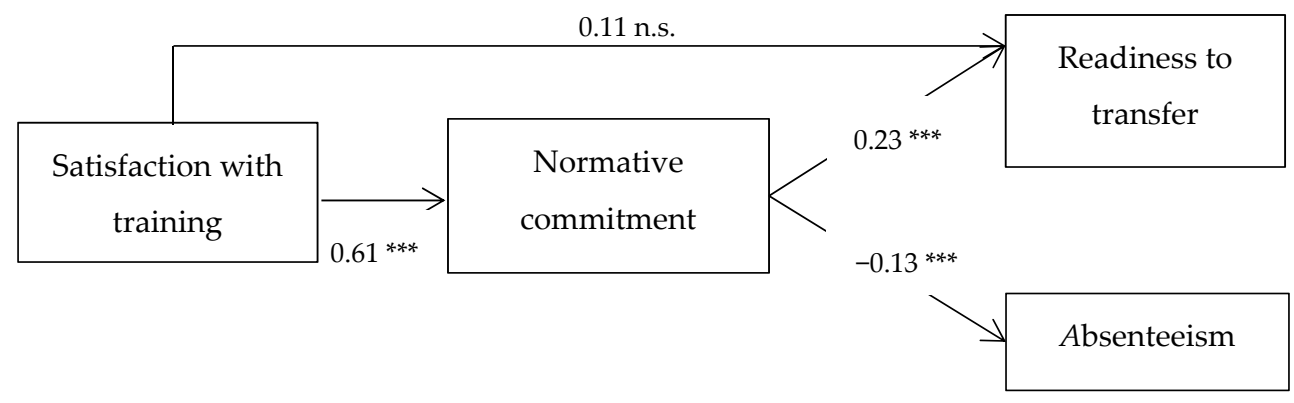

Figure 1. Result of mediation model. (Note: $R^{2}=11 \%$; ${ }^{* * *} p<0.001$; n.s. not significant).

Table 3. The total, indirect and direct effects of the normative commitment as a mediating variable in the context of the relationship between training satisfaction and the readiness to transfer learning.

\begin{tabular}{cccccc}
\hline Effects & Est. & $\begin{array}{c}\text { CI (95\%) } \\
\text { Confidence Intervals } \\
\text { [Lower 5\%, Upper 5\%] }\end{array}$ & S.E. & Est./E.S. & $\begin{array}{c}\text { Two-Tailed } \\
\text { Q-Value }\end{array}$ \\
\hline Total & 0.269 & {$[0.187,0.350]$} & 0.049 & 5.489 & 0.000 \\
Indirect Effect & 0.149 & {$[0.054,0.245]$} & 0.058 & 2.568 & 0.010 \\
Direct Effect & 0.119 & {$[-0.023,0.263]$} & 0.087 & 1.367 & 0.167 \\
\hline
\end{tabular}

Note: Est. = standardized coefficients; S.E. = standard error; $\mathrm{CI}=$ Confidence Intervals.

\section{Discussion}

\subsection{Implications for Research}

Our starting point in this study was the observed contradictory tensions weighing on those in charge of training managers, namely the importance of investing in training and the uncertainties regarding the macro-level benefits for the organization, i.e., performance, profitability, and so on. The intent of our empirical investigation was to contribute to scientific progress in regards to training program benefits by exploring them from a new angle: the individual (micro level) rewards from training practices that benefit the organization (macro level). More specifically, the goal of our study was to clarify, within a mediation model, the relationships between a positive reaction to training (satisfaction with training), normative commitment, the readiness to transfer learning, and absenteeism. In fact, while we know that negative reactions to training are often reflected in a negative impact for the organization or department, "regardless of their relationship with other measures, from a pragmatic perspective, trainee reactions are important. Although positive reactions do not 
guarantee organizational support, negative reactions can often have an adverse effect on the training department" ([17], p. 353). Yet, by which mechanism a positive reaction to training leads to a positive impact for the organization are not known; "because reaction measures are the easiest to collect, it would be ideal if they could be used as surrogate measures of learning and transfer" ([17], p. 352). It is therefore important to understanding the mechanism underlying the relationship between reaction to training and the positive effects on the organization.

In this respect, our findings reveal a moderately positive relationship between satisfaction with training and normative commitment. More particularly, satisfaction with training enhances normative commitment, hence increasing the readiness to transfer learning and reduce absenteeism. Part of our findings is consistent with Barlett's [54] research and the study by Bulut and Culha [59] on the relationship between a number of training-related variables (such as frequency, access, support, motivation, and rewards) and commitment to the organization. Moreover, the significant relationship between normative commitment to the organization on the one hand, and readiness to transfer learning and absenteeism on the other, indicates the impact of the training on the individual, which, in addition, is favorable to the organization in terms of employee willingness to harness learning, and to reduce cognitive or attitudinal withdrawal such as absenteeism, which jeopardizes investment in training. Our findings also support the viability of the total mediation model whereby normative commitment is used as a mediating variable. In clear terms, satisfaction with training impacts readiness to transfer through a normative commitment to the organization. In other words, satisfaction with training creates an obligation with the learner to give back in return for the investment in training; the trained employee becomes motivated to harness learning for the benefit of the organization. In this sense, employee attitudes such as satisfaction with training constitute safety nets in the face of high employee training costs, especially if, in the process, they also boost commitment to the organization [60] and foster transfer of learning. This is an important finding considering the fact that past research has been unable to establish in a satisfactory manner the causality between training and distal results such as organizational performance [61]. Moreover, while out of the three components of organizational commitment, previous research focused extensively on the relationship between employee training and affective commitment and continuance [60,61], while hardly any research addressed the relationship between training and organizational normative commitment [62].

This study therefore makes an effective contribution to recent efforts among researchers to understand the role of normative commitment, an often overlooked aspect in the literature. In addition, the model we tested introduces a new variable - the readiness to transfer learning-which may play an important role in carrying the impact of training from the individual level over to the organizational level. This shift remained difficult to demonstrate [15,17]. Our model uses three theories: the human capital theory [63], for the purpose of explaining the perceived utility of the training by employees in terms of employability; the social exchange theory [31] and the norm of reciprocity in order to ground the moral obligation felt by the employee to give back in one form or another in return for the training received; and the self-determination theory, particularly introjected regulation, explaining the psychological state of readiness to transfer learning. To our knowledge, these findings are a new and fresh contribution to the question of employee training program benefits and transfer of learning.

\subsection{Practical Implications}

The results of this study could support the promotion of training practices. Indeed, these results show that the risk associated with training practices (lack of transfer, absenteeism) is reduced when the employee is satisfied with the training. Our results highlight the importance of reconsidering training program evaluation in terms of benefits drawn by an organization from the positive impact that training has on learner attitudes and behaviors. They suggest that a positive reaction to training will carry over to the organization itself by way of increased employee commitment and reduced absenteeism, which in turn help to alter beliefs in regard to investment in training, encourage skills development practices, and alleviate the cost-benefit tensions that weigh on managers and staff in 
charge of training. Our results also highlight the crucial importance of normative commitment in the social exchange relationship [31] between the employee and the organization. Practitioners should encourage employees to participate in training programs and to use normative commitment as a lever for the transfer of learning. Our findings can also quiet employers' concerns about turnover and the risk that competitors might benefit from the training they have provided to employees [64], insofar as good training practices have a positive impact on employee attitude.

\subsection{Limitations and Future Prospects for Research}

There are a few limitations defining our empirical research. Our data, collected on the basis of a cross-sectional survey design, do not enable us to establish employees' long-term satisfaction with training. Thus, we do not claim to have achieved a causal model. Moreover, the scope of our study is limited to the level of individual analysis given that it comprised a self-reported questionnaire filled out by the employee for his or her organization. Subsequent studies should try to verify the hypotheses at different levels of analysis (organization, department, work team). Differentiated relationships may emerge between satisfaction with training and individual or organizational results depending on the level of analysis applied. These approaches offer avenues for promising future research that can improve our understanding of the Training-Results relationship.

\section{Conclusions}

Several years have passed since the publication of the first Kirkpatrick's model, one of the best-known models for analyzing and evaluating the results of training. But we believe that this model could be improved by investigating the link between the indicators at the individual level and those at the organizational level. This gap could explain the resistance of some organizations to providing training opportunities to their employees. This study offers insights into understanding the complex nature between training and results. Indeed, a human capital theory lens provides an analytical framework to explain the tension created between an organization's need to train its employees and the risk of seeing their competitors recruit their trained employees. Social exchange theory, in essence reciprocity norm, has identified the mechanism by which this tension is absorbed. Our study revealed that positive reactions to training create a psychological state which predisposes employees to transfer learning and to reduce deviant behaviors such as absenteeism. The central role of normative commitment and its predictor (satisfaction with training) opens the way to the integration of Kirkpatrick's model into other explanatory theories such as how to cultivate normative commitment, and how to use normative commitment as an intervention solution to reduce uncertainty in the Training-Results relationship.

Author Contributions: Jamal Ben Mansour and Abdelhadi Naji designed the experiments, performed the experiments, analyzed the data, contributed reagents/materials/analysis tools, and wrote the paper. André Leclerc participated to conceive questionnaire and to collect data. All authors read, revised and approved the final manuscript.

Conflicts of Interest: The authors declare no conflict of interest.

\section{References}

1. Goldstein, I.L. Training in Work Organizations. Annu. Rev. Psychol. 1980, 31, 229-372. [CrossRef]

2. Latham, G.P. Human Resource Training and Development. Annu. Rev. Psychol. 1988, 39, 545-582. [CrossRef]

3. Lawler, E.E.; Mohrman, S.A.; Ledford, G.E., Jr. Strategies for High Performance Organizations; Jossey-Bass.: San Francisco, CA, USA, 1998.

4. Martocchio, J.J.; Baldwin, T.T. The Evolution of Strategic Organizational Training. In Research in Personnel and Human Resource Management; Ferris, R.G., Ed.; JAI Press: Greenwich, CT, USA, 1997; pp. 1-46.

5. Dolezalek, H. 2005 Industry Report. Training 2005, 42, 14-28.

6. Salas, E.; Cannon-Bowers, J.A. The Science of Training: A Decade of Progress. Annu. Rev. Psychol. 2001, 52, 471-499. [CrossRef] [PubMed] 
7. Fossum, J.A.; Arvey, R.D.; Paradise, C.A.; Robbins, M.E. Modeling the Skills Obsolescence Process: A Psychological/Economic Integration. Acad. Manag. Rev. 1986, 11, 362-374.

8. Demartini, C.; Trucco, S. Does Intellectual Capital Disclosure Matter for Audit Risk? Evidence from the UK and Italy. Sustainability 2016, 8, 867. [CrossRef]

9. Aguinis, H.; Kraiger, K. Benefits of Training and Development for Individuals and Teams, Organizations, and Society. Annu. Rev. Psychol. 2009, 60, 451-474. [CrossRef] [PubMed]

10. Baldwin, T.T.; Ford, K.J.; Blume, B.D. Transfer of Training 1988-2008: An Updated Review and Agenda for Future Research. Int. Rev. Ind. Org. Psychol. 2009, 24, 41-70.

11. Arthur, W., Jr.; Bennett, W., Jr.; Edens, P.S.; Bell, S.T. Effectiveness of Training in Organizations: A Meta-Analysis of Design and Evaluation Features. J. Appl. Psychol. 2003, 88, 234-245. [CrossRef] [PubMed]

12. Burke, M.J.; Day, R.R. A Cumulative Study of the Effectiveness of Managerial Training. J. Appl. Psychol. 1986, 71, 232-245. [CrossRef]

13. Guzzo, R.A.; Jette, R.D.; Katzell, R.A. The Effects of Psychologically Based Intervention Programs on Worker Productivity: A Meta-Analysis. Pers. Psychol. 1985, 38, 275-291. [CrossRef]

14. Tharenou, P.; Saks, A.M.; Moore, C.A. Review and Critique of Research on Training and Organizational-Level Outcomes. Hum. Resour. Manag. Rev. 2007, 17, 251-273. [CrossRef]

15. Colquitt, J.A.; LePine, J.A.; Noe, R.A. Toward an Integrative Theory of Training Motivation: A Meta-Analytic Path Analysis of 20 Years of Research. J. Appl. Psychol. 2000, 85, 678-707. [CrossRef] [PubMed]

16. Alliger, G.M.; Janak, E.A. Kirkpatrick's Levels of Training Criteria: Thirty Years Later. Pers. Psychol. 1989, 42, 331-342. [CrossRef]

17. Alliger, G.M.; Tannenbaum, S.I.; Bennett, W.J.; Traver, H.; Shotland, A. A Metaanalysis of the Relations among Training Criteria. Pers. Psychol. 1997, 50, 341-358. [CrossRef]

18. Paauwe, J. HRM and Performance: Achievements, Methodological Issues and Prospects. J. Manag. Stud. 2009, 46, 129-142. [CrossRef]

19. Alfes, K.; Parfyonova, A.D.; Truss, C.; Soane, E.C. The Link between Perceived Human Resource Management Practices, Engagement and Employee Behaviour: A Moderated Mediation Model. Int. J. Hum. Resour. Manag. 2013, 24, 330-351. [CrossRef]

20. Gratton, L.; Truss, C. The Three-Dimensional People Strategy: Putting Human Resources Policies into Action. Acad. Manag. Exec. 2003, 17, 74-86. [CrossRef]

21. Conway, E.; Monks, K. HR Practices and Commitment to Change: An Employee-Level Analysis. Hum. Resour. Manag. J. 2008, 18, 72-89. [CrossRef]

22. Snape, E.; Redman, T. HRM Practices, Organizational Citizenship Behaviour, and Performance: A Multi-Level Analysis. J. Manag. Stud. 2010, 47, 1219-1247. [CrossRef]

23. Schultz, T.W. Investment in human capital. Am. Econ. Rev. 1961, 51, 1-17.

24. Becker, G.S. Human Capital: A Theoretical and Empirical Analysis, with Special Reference to Education; The University of Chicago Press: Chicago, IL, USA, 1964.

25. Vidotto, J.D.F.; Ferenhof, H.A.; Selig, P.M.; Bastos, R.C. A human capital measurement scale. J. Intell. Cap. 2017, 18, 316-329. [CrossRef]

26. Scafarto, V.; Ricci, F.; Scafarto, F. Intellectual capital and firm performance in the global agribusiness industry: The moderating role of human capital. J. Intell. Cap. 2016, 17, 530-552. [CrossRef]

27. Salau, O.P.; Falola, H.O.; Ibidunni, A.S.; Igbinoba, E.E. Exploring the Role of Human Capital Management on Organizational Success: Evidence from Public Universities. Manag. Dyn. Knowl. Econ. 2016, 4, 493-513.

28. Gouldner, A.W. The norm of reciprocity: A preliminary statement. Am. Sociol. Rev. 1960, 25, 161-178. [CrossRef]

29. Homans, G.C. Social behavior as exchange. Am. J. Sociol. 1958, 63, 597-606. [CrossRef]

30. Thibault, J.W.; Kelley, H.H. The Social Psychology of Groups; John Wiley: New York, NY, USA, 1959.

31. Blau, P.M. Exchange and Power in Social Life; John Wiley: New York, NY, USA, 1964.

32. Cropanzano, R.; Mitchell, M.S. Social exchange theory: An interdisciplinary review. J. Manag. 2005, 31, 874-900. [CrossRef]

33. Maxwell, S.; Nye, P.; Maxwell, N. The wrath of the fairness-primed negotiator when the reciprocity norm is violated. J. Bus. Res. 2003, 56, 399-409. [CrossRef]

34. Spector, P. Job Satisfaction: Application, Assessment, Causes and Consequences; Sage: Thousand Oaks, CA, USA, 1997. 
35. Schmidt, S.W. The Relationship between Satisfaction with Workplace Training and Overall Job Satisfaction. Hum. Resour. Dev. Q. 2007, 18, 481-498. [CrossRef]

36. Kirkpatrick, D.L. Evaluation of Training. In Training and Development Handbook: A Guide to Human Resources Development; Craig, R.L., Ed.; McGraw-Hill: New York, NY, USA, 1976.

37. Baldwin, T.; Ford, J.K. Transfer of Training: A Review and Directions for Future Research. Pers. Psychol. 1988, 41, 63-105. [CrossRef]

38. Rivard, P.; Lauzier, M. La Gestion De La Formation Et Du Développement Des Ressources Humaines, 2nd ed.; Presse de l'Université du Québec: Québec, QC, Canada, 2013.

39. Beller, E.K. The Concept Readiness and Several Application. Read. Teach. 1970, 23, 727-765.

40. Tannenbaum, S.I.; Mathieu, J.E.; Salas, E.; Cannon-Bowers, J.A. Meeting Trainees' Expectations: The Influence of Training Fulfillment on the Development of Commitment, Self-Efficacy, and Motivation. J. Appl. Psychol. 1991, 76, 759-769. [CrossRef]

41. Mowday, R.T.; Porter, L.W.; Steers, R.M. Employee-Organization Linkages: The Psychology of Commitment, Absenteeism, and Turnover; Academic Press: New York, NY, USA, 1982; p. 253.

42. O'Reilly, C., III; Chatman, J. Organizational Commitment and Psychological Attachment: The Effects of Compliance, Identification, and Internalization on Prosocial Behavior. J. Appl. Psychol. 1986, 71, 492-499.

43. Meyer, J.P.; Allen, N.J. Testing the "Side-Bet Theory" of Organizational Commitment: Some Methodological Considerations. J. Appl. Psychol. 1984, 69, 372-378. [CrossRef]

44. Meyer, J.P.; Allen, N.J. A Three-Component Conceptualization of Organizational Commitment. Hum. Resour. Manag. Rev. 1991, 1, 61-89. [CrossRef]

45. Wiener, Y. Commitment in Organizations: A Normative View. Acad. Manag. Rev. 1982, 7, 418-428.

46. Wiener, Y.; Vardi, Y. Relationships between Job, Organization, and Career Commitments and Work Outcomes: An Integrative Approach. Org. Behav. Hum. Perform. 1980, 26, 81-96. [CrossRef]

47. Scholl, R.W. Differentiating Commitment from Expectancy as a Motivating Force. Acad. Manag. Rev. 1981, 6, 589-599.

48. Meyer, J.P.; Allen, N.J. Commitment in the Workplace: Theory, Research, and Application; Sage Publications: Thousand Oaks, CA, USA, 1997.

49. Meyer, J.P.; Herscovitch, L. Commitment in the Workplace: Toward the General Model. Hum. Resour. Manag. Rev. 2001, 11, 299-326. [CrossRef]

50. Meyer, J.P.; Parfyonova, N.M. Normative Commitment in the Workplace: A Theoretical Analysis and Re-Conceptualization. Hum. Resour. Manag. Rev. 2010, 20, 283-294. [CrossRef]

51. Deci, E.L.; Ryan, R.M. Intrinsic Motivation and Self-Determination in Human Behavior; Plenum Press: New York, NY, USA, 1985.

52. Ryan, R.M.; Deci, E.L. Self-Determination Theory and the Facilitation of Intrinsic Motivation, Social Development, and Well-Being. Am. Psychol. 2000, 55, 68-78. [CrossRef] [PubMed]

53. Meyer, J.P.; Becker, T.E.; Vandenberghe, C. Employee Commitment and Motivation: A Conceptual Analysis and Integrative Model. J. Appl. Psychol. 2004, 89, 991-1007. [CrossRef] [PubMed]

54. Bartlett, K.R. The Relationship between Training and Organizational Commitment: A Study in the Health Care Field. Hum. Resour. Dev. Q. 2001, 12, 335-352. [CrossRef]

55. Meyer, J.P.; Allen, N.J.; Smith, C.A. Commitment to Organizations and Occupations: Extension and Test of a Three-Component Conceptualization. J. Appl. Psychol. 1993, 78, 538-551. [CrossRef]

56. Statistics Canada. Absence Rates for Full-Time Employees by Industry and Sector. Available online: http:/ /www.statcan.gc.ca/pub/75-001-x/2012002/tables-tableaux/11650/tbl-3-fra.htm (accessed on 14 January 2017).

57. Tabachnick, B.G.; Fidell, L.S. Using Multivariate Analysis, 5th ed.; Allyn and Bacon: Boston, MA, USA, 2007.

58. Hayes, A.F. Introduction to Mediation, Moderation and Conditional Process Analysis; The Guilford Press: New York, NY, USA, 2013.

59. Bulut, C.; Culha, O. The Effects of Organizational Training on Organizational Commitment. Int. J. Train. Dev. 2010, 14, 309-332. [CrossRef]

60. Ismail, H.N. Training and Organizational Commitment: Exploring the Moderating Role of Goal Orientation in the Lebanese Context. Hum. Resour. Dev. Int. 2016, 19, 152-177. [CrossRef] 
61. Newman, A.; Thanacoody, R.; Hui, W. The Impact of Employee Perceptions of Training on Organizational Commitment and Turnover Intentions: A Study of Multinationals in the Chinese Service Sector. Int. J. Hum. Resour. Manag. 2011, 22, 1765-1787. [CrossRef]

62. Bashir, N.; Sang Long, C. The Relationship between Training and Organizational Commitment among Academicians in Malaysia. J. Manag. Dev. 2015, 34, 1227-1245. [CrossRef]

63. Becker, G.S. Human Capital, 3rd ed.; The University of Chicago Press: Chicago, IL, USA, 1993.

64. Mello, J. Strategic Human Resource Management, 3rd ed.; South-Western Cengage Learning: Mason, $\mathrm{OH}$, USA, 2011. article distributed under the terms and conditions of the Creative Commons Attribution (CC BY) license (http:/ / creativecommons.org/licenses/by/4.0/). 